\title{
Monitoring of a Hemp Lime External Building Insulation
}

\author{
Georges Costantine*, Chadi Maalouf, Tala Moussa, Guillaume Polidori \\ ${ }^{1}$ Research Group of Engineering Sciences, GRESPI, SFR Condorcet FR CNRS 3417, University of Reims-Champagne-Ardenne, \\ 51 687, Reims, France
}

\begin{abstract}
In a context of promoting energy efficiency, building sector has undergone a notable evolution towards innovative construction insulation materials such as hemp concrete, in order to reduce buildings energy bills and environmental impact. Hemp-Concrete finds application as internal or external thermal insulator in wooden frame walls. In that context, a French building in Grand-Est region, employing HempConcrete as an external insulator is selected and studied. An apartment is monitored for several months. Indoor temperatures, and relative humidities as well as external weather conditions are measured using sensors installed inside the apartment and a weather station placed at the building roof. Indoor comfort analysis shows satisfactory results according to ASHREA standards. Experimental approach is then coupled with a numerical validation at room scale using SPARK simulation tool. Investigations are conducted on indoor office air temperature and relative humidity. Results show a good agreement between numerical values and experimental measurements.
\end{abstract}

\section{Introduction}

From the "Grenelle de l'environnement" [1] in 2007 to the "COP21" in 2015, environmental concerns in France to preserve global resources have largely contributed to recognize bio-based materials as potential natural resources to exploit. The results of numerous research studies in this respect have proved their reliability and advantages in several fields: chemical industry, agriculture, transport, packaging, as well as in construction [2]. In this context, hemp concrete have become widespread in construction field. While literature presents numerous studies of hemp concrete on the intrinsic material [3][4] and wall scales [5][6][7][8], its hygrothermal behaviour at building scale and for long duration is always less studied [9][10][11].

This work aims then to fill these gaps by studying a building using hemp concrete as external insulation. An apartment of the building, located in Fleury-La-Rivière, a town of Epernay in France North-East, is chosen to be instrumented. Temperature and relative humidity probes are installed in different rooms. Flowmeters are also fixed on building south facade in order to quantify thermal losses through the envelope. Outdoor weather conditions are covered by a weather station placed at building roof.

A thermal comfort analysis in the apartment is then established. Results show acceptable levels of temperature and humidity of indoor air according to ASHRAE [12]. Then, a numerical validation is carried out at room scale, particularly in the apartment office by using SPARK simulation tool. Numerical outputs are able to predict experimental data while paying particular attention to room occupancy scenario and convective exchange coefficients between the walls and indoor ambiance.

\section{Experimental approach}

\subsection{Envelope composition}

Building envelope consists of four layers as shown in Figure 1 and Table 1 below. Materials properties are provided by the constructor. Hemp concrete, used as exterior insulation, is projected on site in the walls. Building apartments are equipped with electric radiators for heating and mechanical ventilation systems. A survey of inhabitants comfort conditions led to the selection of a $92.30 \mathrm{~m}^{2}$ apartment occupied by a three-member family with two dogs. It consists of a living room opened to the kitchen, two bedrooms, an office and a bathroom.

D: outer side

A: inner side

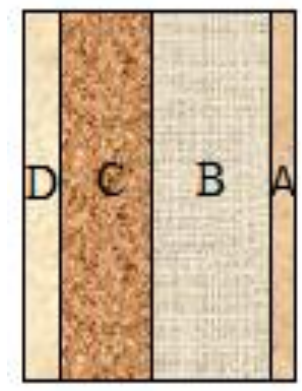

Fig. 1. Wall composition

Corresponding author: georges.costantine@univ-reims.fr 
Table 1. Wall composition.

\begin{tabular}{|c|c|c|c|}
\hline Materials & $\begin{array}{l}\text { Thickness } \\
\text { (cm) }\end{array}$ & $\begin{array}{l}\text { Density } \\
\left(\mathrm{kg} \cdot \mathrm{m}^{-3}\right)\end{array}$ & $\begin{array}{c}\text { Thermal } \\
\text { conductivity } \\
\left(\mathbf{W} \cdot \mathbf{m}^{-1} \cdot K^{-1}\right)\end{array}$ \\
\hline A: gypsum & 0.015 & 900 & 0.25 \\
\hline B: Optibric ${ }^{\circledR}$ & 0.20 & 700 & $\mathrm{R}_{\mathrm{eq}}=1.07$ \\
\hline $\begin{array}{l}\text { C: Hemp } \\
\text { concrete }\end{array}$ & 0.13 & 450 & 0.095 \\
\hline D: Lime sand & 0.02 & 1650 & 0.4 \\
\hline
\end{tabular}

\subsection{Apartment monitoring}

A weather station fixed on the building roof records data relating to the outside climate (temperature, relative humidity, rainfall, radiation, air velocity ...). Inside the apartment, three temperature globe measure radiant temperature in the living room, office and parents' bedroom. Four thermo-hygrometers measure indoor air temperature and relative humidity in the living room, office and two bedrooms. Moreover, three flowmeters placed on the office south façade inner wall record heat losses through the envelope. Sensors are connected to a console recording data wirelessly. Data recorded are covered every month between November 2015 and September 2016. Experimental equipment is shown in figures below.

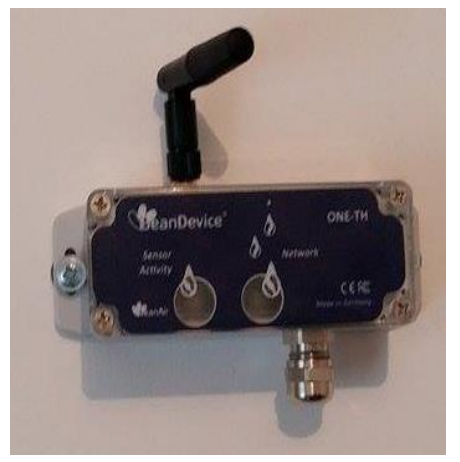

Fig. 2. Thermo-hygrometer

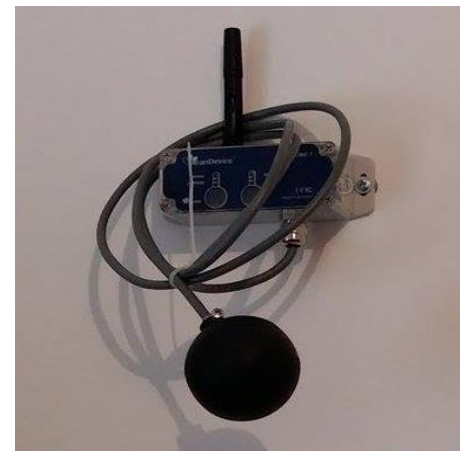

Fig. 3. Temperature globe

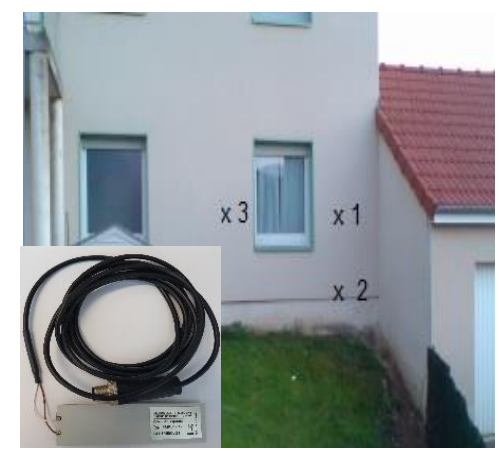

Fig.4. Flowmeters

\subsection{Comfort analysis}

Psychrometric diagrams inside each room give an idea about indoor comfort felt by occupants. In this regard, operating temperature $\left(T_{0}\right)$ is calculated based on dry air temperature $\left(T_{a}\right)$ given by thermo-hygrometers and radiant room temperature $\left(T_{r}\right)$ deduced from the one measured by globe temperature sensors as detailed below [13]:

$$
T_{o}=T_{a}+(1-A)\left(T_{r}-T_{a}\right)
$$

$\mathrm{A}$ is a coefficient that depends on air speed $(\mathrm{A}=0.5$ in winter when windows are closed and $\mathrm{A}=0.7$ in summer when the windows are opened). Below are presented psychrometric diagrams for the living room and parents' bedroom.

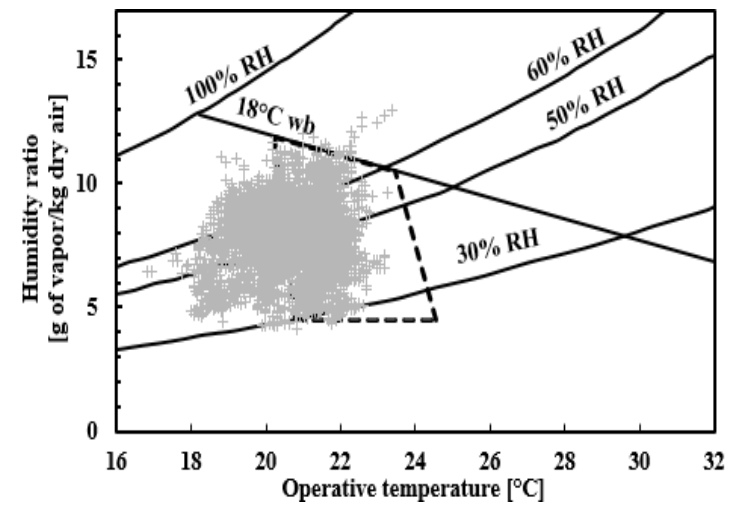

Fig.5. Psychrometric chart for living room during winter

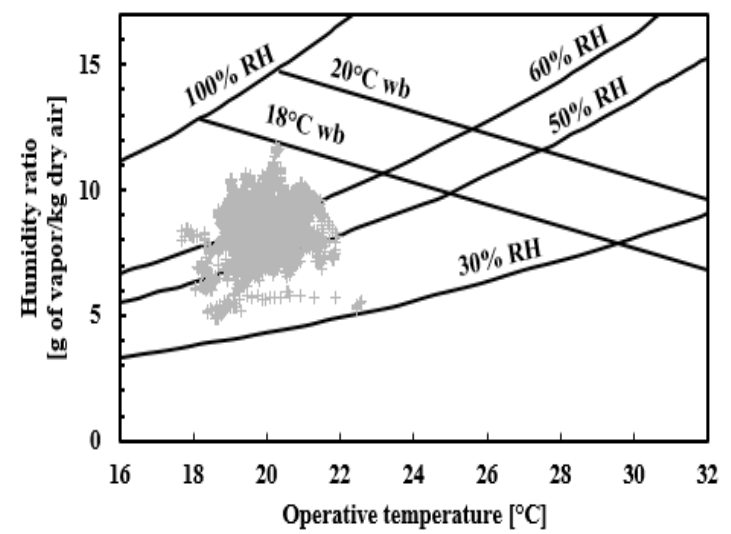

Fig.6. Psychrometric chart for parents' bedroom during winter 


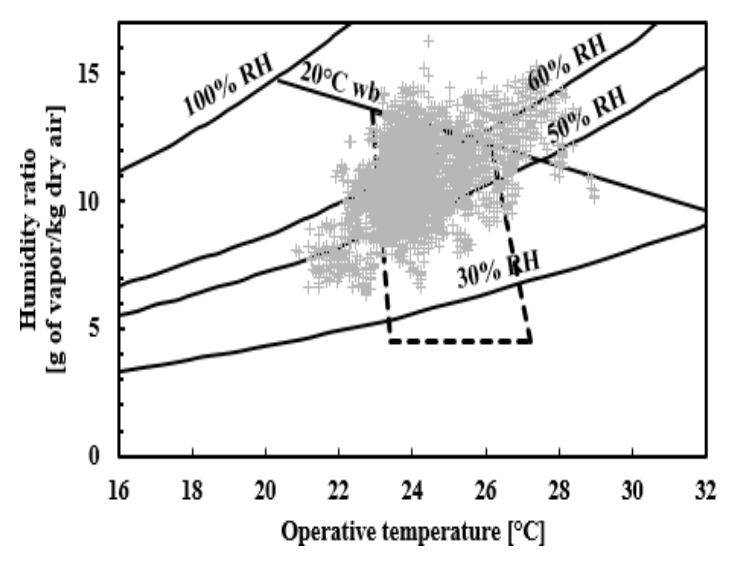

Fig.7. Psychrometric chart for living room during summer

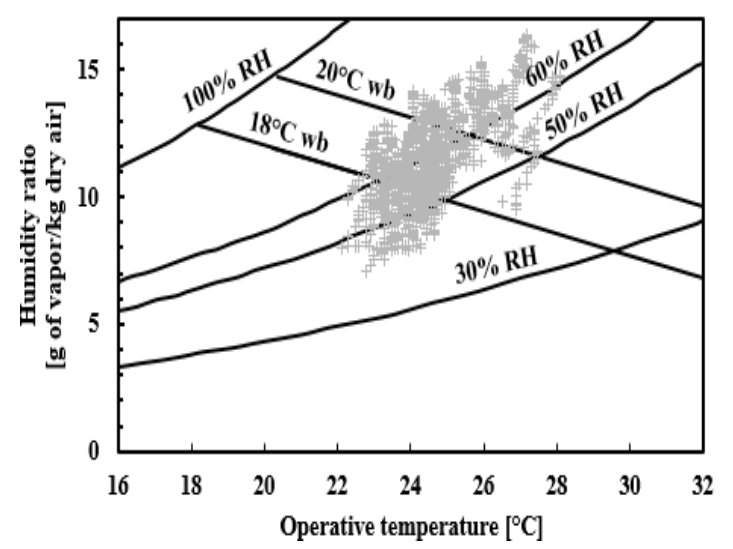

Fig.8. Psychrometric chart for parents' bedroom during summer

Referring to the ASHRAE fundamentals [12], acceptable temperature and humidity ranges for people wearing typical winter and summer clothing during mostly sedentary activity are shown in Fig. 5 and 7. Relative humidity levels are generally acceptable, high values $(>70 \%)$ are detected few times due to the fact that the kitchen is open to the living room and that the cooking activity is often done with closed air vent. In addition to the fact of drying the laundry inside the living room. Moreover, points on the diagram where a drop in temperature (below $21{ }^{\circ} \mathrm{C}$ ) is observed in winter correspond to holiday period during which heaters are turned off. In summer, high indoor temperature values are detected during the heat waves period where outdoor temperature exceeds $35^{\circ} \mathrm{C}$.

For the parents' bedroom, room ventilation is also not insured. In addition, the presence of both dogs with parents is a non-negligible source of vapor generation in the air, resulting in high relative humidity levels in summer or winter. Concerning thermal comfort in the bedrooms, studies related to this axis are limited. Maximum summer comfort temperature is estimated at $26{ }^{\circ} \mathrm{C}$ by the CIBSE [14]. Similarly, ASHRAE 55-2004 [15] indicates that high summer temperatures are acceptable in the presence of a fan. In winter, CIBSE reports a minimum comfort temperature of $17^{\circ} \mathrm{C}$, while World Health Organization recommends a minimum temperature of $16{ }^{\circ} \mathrm{C}$ in order to avoid respiratory infections below this temperature. Based on upon the findings, indoor temperature conditions in the apartment are acceptable.

\subsection{Heat losses analysis}

Three flowmeters installed on the interior office south facade allow to measure heat fluxes through the wall. Flowmeters 1 and 3 are placed at a height of $1.20 \mathrm{~m}$ on both sides of the window and Flowmeter_ 2 is placed at the plinth (see Fig.4). Recordings are done firstly for flowmeters 1 and 2 (between 01/12/2015 and $15 / 12 / 2015$ ) and for flowmeters 1 and 3 (between $16 / 12 / 2015$ and 11/01/2016) later on. Results are shown in Fig. 8 and 9.

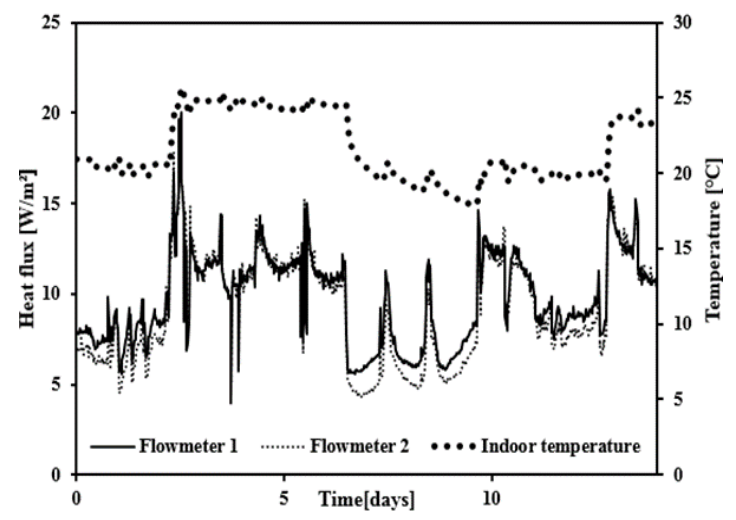

Fig.8. Experimental thermal fluxes and temperature in the office (Dec. $1^{\text {st }}-$ Dec. $15^{\text {th }} 2015$ )

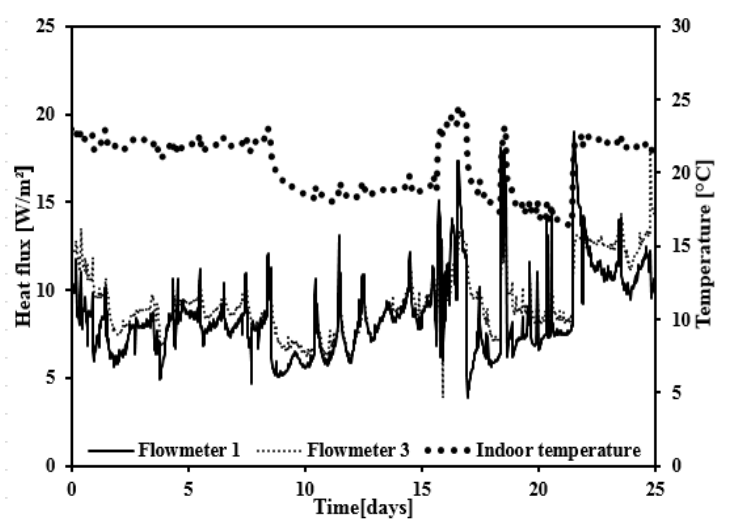

Fig.9. Experimental thermal fluxes and temperature in the office (Dec. $16^{\text {th }} 2015-$ Jan. $11^{\text {th }} 2016$ )

Heat fluxes are driven by indoor temperature variation in both periods which is consistent, as being proportional to temperature gradient between inner surface and indoor air. Then, during the first period, the flux is fairly homogeneous over the wall height (average value of $9.71 \mathrm{~W} . \mathrm{m}^{-2}$ for flowmeter 1 and $9.15 \mathrm{~W} . \mathrm{m}^{-2}$ for flowmeter 2). On the other hand, thermal losses recorded by flowmeter 3 in the second period (average of 9.59 $\mathrm{W} . \mathrm{m}^{-2}$ ) are globally higher than those of flowmeter 1 (average of $8.69 \mathrm{~W} \cdot \mathrm{m}^{-2}$ ). This can be attributed to flowmeter 3 position at the middle of the facade, which makes it more exposed to wind and driving rain, and 
thus increases envelope thermal conductivity and heat losses.

\section{Numerical modelling at room scale}

The studied room in this part is the office. It is an office of $2.8 \times 3.3 \times 2.5 \mathrm{~m}^{3}$. South facade contains double glazing window of $1.25 \times 1.1 \mathrm{~m}^{2}$. East facade is in partition with a garage, while the other two are considered as partition walls. Office is supposed to be occupied every day by a single person between $14 \mathrm{~h}$ and 18h. Main heat sources are due to the lighting and the computer. Initial room thermal inertia is $\mathrm{I}=500000$ $\mathrm{J}^{\mathrm{K}} \mathrm{K}^{-1}$. Heat transfer convection coefficients of vertical walls ( $\mathrm{h}_{\text {conv_int }}$ ), ceiling ( $\left.\mathrm{h}_{\text {conv_ceiling }}\right)$ and floor ( $\left.\mathrm{h}_{\text {conv_floor }}\right)$ are calculated as follows:

$$
\begin{gathered}
h_{\text {conv_int }}=1.235\left(T_{i}-T_{s i}\right)^{0.25} \exp (0.0467 H) \\
h_{\text {conv_ceiling }}=\left[\left(1.5\left(\left(T_{i}-T_{s i}\right) / H\right)^{0.25}\right)\right)^{6}+ \\
\left.\left(1.23\left(T_{i}-T_{s i}\right)^{1 / 3}\right)^{6}\right]^{\wedge 1 / 6} \text { if } T_{i}>T_{s i} \\
h_{\text {conv_ceiling }}=0.6\left(T_{i}-T_{s i}\right)^{0.2} \text { if } T_{i}<T_{s i} \\
h_{\text {conv_floor }}=1.8\left|T_{i}-T_{s i}\right|^{1 / 3}
\end{gathered}
$$

$\mathrm{T}_{\mathrm{i}}$ being indoor air temperature, $\mathrm{T}_{\mathrm{si}}$ inner surface temperature and $\mathrm{H}$ the wall height. External convection coefficients $\left(\mathrm{h}_{\text {conv_ext }}\right)$ are deduced based on outside air velocity $(\mathrm{V})$ and direction:

$$
\begin{gathered}
h_{\text {conv_ext }}=1.7(1.8 \times V+0.2)+5.1 \text { for a } \\
\text { façade facing wind } \\
h_{\text {conv_ext }}=1.7(0.4 \times V+1.7)+5.1 \text { for a non- } \\
\text { exposed façade }
\end{gathered}
$$

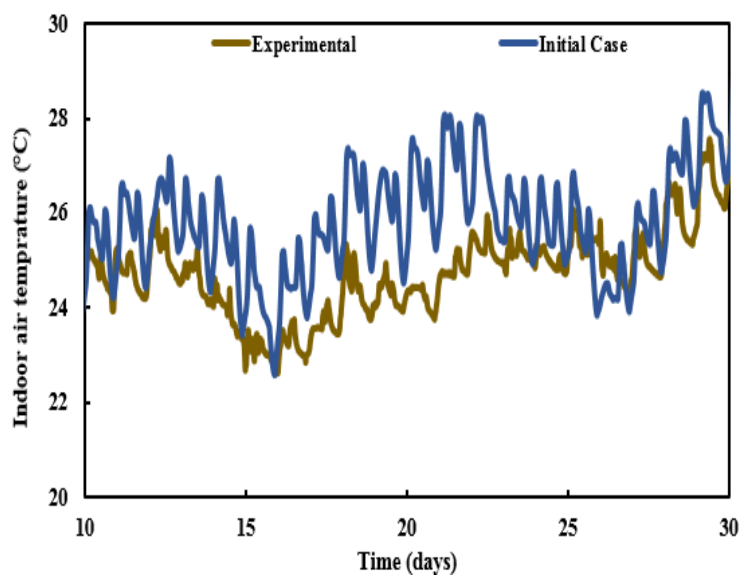

Fig.10. Comparison between experimental and numerical indoor temperature

Outdoor weather conditions including temperature, relative humidity and radiation density are models inputs. The modeling of heat and moisture transfer as well as the energy and mass conservation equations are detailed in [16]. An initial simulation case is tested.
Simulated indoor air temperatures and humidities are compared to the experimental data in Fig. 10 and 11 for a 20 days period during summer season.

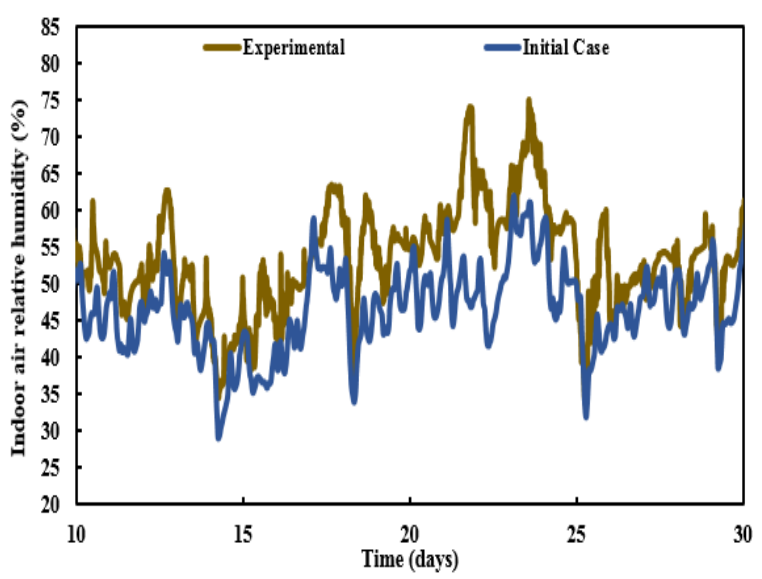

Fig.11. Comparison between experimental and numerical indoor relative humidity

Fig. 10 and 11 show that indoor temperature is globally overestimated (and thus relative humidity is underestimated). For greater understanding, a parametric study is carried out by varying room thermal inertia, indoor heat and vapour sources, and internal heat transfer convection coefficient for vertical walls. Different cases are summarized in Table 2 and results are shown in Fig.12 and 13.

Table 2. Case studies at room scale.

\begin{tabular}{|c|c|c|c|}
\hline Cases & Description & $\begin{array}{c}\text { Mean } \\
\text { indoor } \\
\mathbf{T}\left({ }^{\circ} \mathbf{C}\right)\end{array}$ & $\begin{array}{c}\text { Mean } \\
\text { indoor } \\
\mathbf{R . H}(\%)\end{array}$ \\
\hline Exp. & Experimental data & 24,80 & 53,23 \\
\hline Initial & Initial simulation case & 25,73 & 47,08 \\
\hline Case_1 & $\begin{array}{c}\text { Room thermal inertia } \\
\text { is multiplied by 5 }\end{array}$ & 25,78 & 46,96 \\
\hline Case_2 & $\begin{array}{c}\text { Heat and moisture } \\
\text { sources are omitted }\end{array}$ & 25,16 & 47,68 \\
\hline Case_3 & $\mathrm{h}_{\text {conv int }}=4.5$ & 24,24 & 51,46 \\
\hline
\end{tabular}

Increasing room thermal inertia (Case_1) decreases internal temperature fluctuations and reduces its amplitude of variations without affecting its average value $\left(25.73{ }^{\circ} \mathrm{C}\right.$ in the initial case and $25.78{ }^{\circ} \mathrm{C}$ in Case_1).

However, neglecting indoor heat and moisture sources (Case_2) entails a drop in mean air temperature by $0.56{ }^{\circ} \mathrm{C}$ due to the fact that heat released is reduced in the room. This emphasizes the importance of occupancy scenario in the room which is variable according to inhabitants' activities.

Moreover, in the correlation of $\mathrm{h}_{\text {conv int }}$ (eq. 2), vertical walls convection coefficient lays between 2 and 
$2.2 \mathrm{~W} \cdot \mathrm{m}^{-2} \cdot \mathrm{K}^{-1}$. Once increased to $4.5 \mathrm{~W} \cdot \mathrm{m}^{-2} \cdot \mathrm{K}^{-1}$ (and this is justified by opened windows in summer and thus a higher speed of the air) (Case 3), convective exchanges between indoor air and wall inner surface are increased. Thus, temperature gradient considered is reduced and average indoor air temperature decreases by $1.5{ }^{\circ} \mathrm{C}$. In addition, Cas 3 reproduces well the dynamic variations of internal temperature measured in terms of amplitude and phase shift.

Observations noted for indoor air relative humidity are similar (Fig. 13). Case_3 shows the most satisfactory results in comparison with experimental data giving an average relative humidity of $51.46 \%$. Thermal inertia of the office (Case_1) has a reduced impact on the relative humidity compared to its influence on indoor air temperature. By neglecting heat and moisture sources (Case_2), relative humidity increases by $0.60 \%$ compared to the initial case because of temperature decrease in this case.

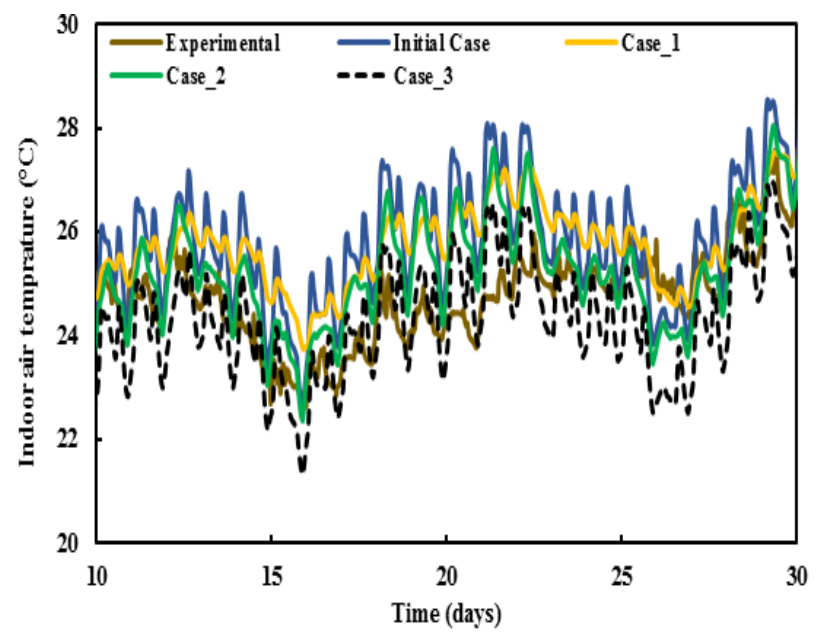

Fig.12. Comparison between experimental and numerical indoor temperature for different case studies

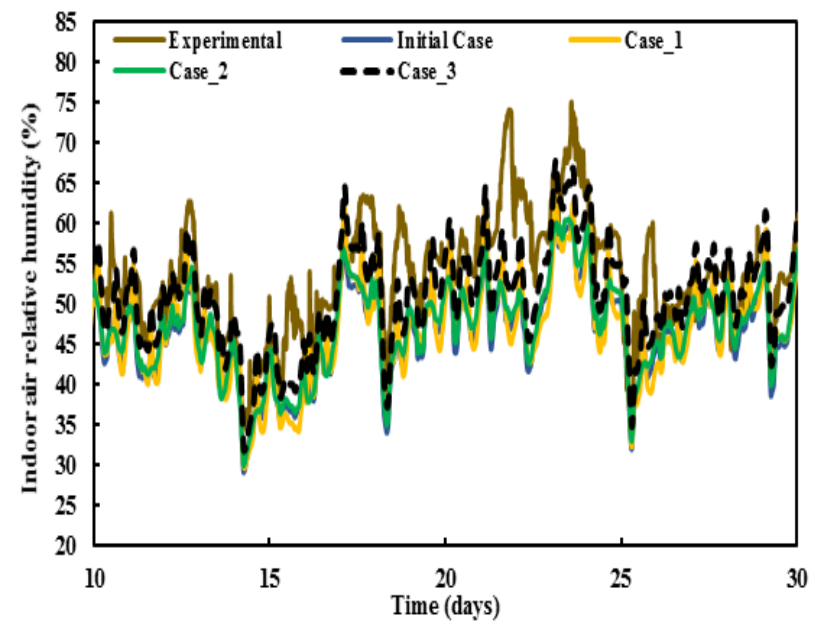

Fig.13. Comparison between experimental and numerical indoor relative humidity for different case studies

Based on the previous analysis and taking into account hygrometers accuracy, Case_3 seems the most suitable for modelling temperature and relative humidity variations in the studied room. It follows that a suitable combination of inner walls convective transfer coefficients and room occupancy scenario is crucial to improve model outputs.

\section{Conclusion}

This work presents the study of a building located in the north-east of France and using hemp concrete as external insulation. An apartment of the building is selected and instrumented. Experimental data are analyzed and then coupled to a numerical validation at the office scale. Investigations are conducted on indoor temperature and relative humidity.

Psychrometric diagrams in different apartment rooms show acceptable comfort levels. High relative humidities are due to inhabitants' behavior towards their apartment. In addition, flowmeters measurements indicate an overall homogeneity over wall height. Moreover, at the office scale, numerical model simulated using SPARK tool shows an acceptable agreement between experimental measurements and numerical results. However, mastering room occupancy scenarios and convective heat transfer phenomena between inner surface and indoor ambiance are two essential parameters to improve model results.

\section{Acknowledgment}

This work is carried out in the scope of a doctoral project funded by "Le FEDER" (European funds for Regional Development) and in collaboration with "Le Foyer Rémois" social landlord.

\section{References}

[1] 2015 Grenelle 1 Enivronnement, "Le Grenelle 1 Enivronnement," 2010.

[2] A.-M. Nuyttens, "Production, transformation et utilisation des matériaux biosourcés pour la construction: quelles actions de la Région Ilede-France ?," 2017.

[3] F. Collet and S. Pretot, "Thermal conductivity of hemp concretes: Variation with formulation, density and water content," Constr. Build. Mater., vol. 65, pp. 612-619, 2014.

[4] S. Elfordy, F. Lucas, F. Tancret, Y. Scudeller, and L. Goudet, "Mechanical and thermal properties of lime and hemp concrete ('hempcrete') manufactured by a projection process," Constr. Build. Mater., vol. 22, no. 10, pp. 2116-2123, Oct. 2008.

[5] A. D. Tran Le, C. Maalouf, T. H. Mai, E. Wurtz, and F. Collet, "Transient hygrothermal behaviour of a hemp concrete building envelope," Energy Build., vol. 42, no. 10, pp. 1797-1806, Oct. 2010.

[6] G. Costantine, C. Maalouf, E. Kinab, and G. Polidori, "Numerical study of a hemp concrete 
wall," in Advanced Buildins Skins ABS, 2016.

[7] D. Lelievre, T. Colinart, and P. Glouannec, "Hygrothermal behavior of bio-based building materials including hysteresis effects: Experimental and numerical analyses," Energy Build., vol. 84, pp. 617-627, Dec. 2014.

[8] Y. A. Ouméziane, S. Moissette, M. Bart, and C. Lanos, "Effect of coating on the hygric performance of a hemp concrete wall," pp. 109116, 2012.

[9] F. Bennai, N. Issaadi, K. Abahri, R. Belarbi, and A. Tahakourt, "Experimental characterization of thermal and hygric properties of hemp concrete with consideration of the material age evolution," Heat Mass Transf., pp. 1-9, Nov. 2017.

[10] G. Costantine, C. Maalouf, T. Moussa, and G. Polidori, "Experimental and numerical investigations of thermal performance of a Hemp Lime external building insulation," Build. Environ., vol. 131, pp. 140-153, Mar. 2018.

[11] B. Moujalled, Y. Aït Ouméziane, S. Moissette, M. Bart, C. Lanos, and D. Samri, "Experimental and numerical evaluation of the hygrothermal performance of a hemp lime concrete building: A long term case study," Build. Environ., vol. 136, pp. 11-27, May 2018.

[12] ASHRAE, ASHRAE HANDBOOK FUNDAMENTALS, SI Edition. 2013.

[13] M. Kazkaz and M. Pavelek, "OPERATIVE TEMPERATURE AND GLOBE TEMPERATURE," Eng. Mech., vol. 204, no. 3, pp. 319-325, 2013.

[14] CIBSE, "Environmental Design, Chartered Institution of Building Services Engineers," London, 2006.

[15] B. W. Olesen, "International standards for the indoor environment," Indoor Air, vol. 14, no. s7, pp. 18-26, Aug. 2004.

[16] G. Costantine, C. Maalouf, E. Kinab, and G. Polidori, "Numerical Investigation of the Hygrothermal Behaviour of a Hemp-Concrete Room: Hysteresis Effect of the Sorption Isotherm and its Temperature Dependency," in Building Simualtion, 2017. 